\title{
O MÉTODO BicK DE OBSERVAÇÃO DE BEBÊS COMO MÉTODO DE PESQUISA
}

\author{
Lisiane Machado de Oliveira-Menegotto* \\ Clarissa Corrêa Menezes** \\ Nara Amália Caron*** \\ Rita de Cássia Sobreira Lopes****
}

\section{RESUMO}

O artigo apresenta uma discussão sobre o potencial do método Bick de observação de bebês como método de pesquisa. Desenvolvemos uma descrição do método desde a sua criação, buscando possíveis aproximaçôes com a clínica e com a pesquisa. Além disso, discutimos os aspectos éticos do método Bick de observação aplicado à pesquisa. O método Bick de observação tem conquistado cada vez mais reconhecimento, sendo aplicado à pesquisa, em função de seu potencial de gerar novas idéias e contribuir com discussões teóricas no âmbito da Psicologia do Desenvolvimento e, sobretudo, da Psicanálise.

Palavras-chave: método Bick, método de pesquisa, observação de bebês

* Psicóloga Clínica; Mestre e Doutoranda em Psicologia do Desenvolvimento do Curso de Pós-Graduação em Psicologia do Desenvolvimento da Universidade Federal do Rio Grande do Sul.

** Psicóloga (UFRGS); Especialista em Psicologia Clínica com ênfase em Terapia Familiar e de Casal (DOMUS - Centro de Terapia de Família e de Casal); Mestre e Doutoranda em Psicologia do Desenvolvimento do Curso de Pós-Graduação em Psicologia do Desenvolvimento da Universidade Federal do Rio Grande do Sul.

*** Médica psiquiatra; Psicanalista de crianças e adolescentes; Membro efetivo da Sociedade Psicanalítica de Porto Alegre.

**** Doutora pela University College London (Inglaterra); Pesquisadora do CNPq; Professora do Curso de Pós-Graduação em Psicologia do Desenvolvimento da Universidade Federal do Rio Grande do Sul. 


\begin{abstract}
THE BICK METHOD OF INFANT OBSERVATION AS A RESEARCH METHOD

The article presents a discussion concerning the potentialities of the Bick method of infant observation as a research method. A description of the method since its creation is presented, and the possible approximations with clinical work and research are highlighted. In addition, the ethical aspects of the Bick method applied to research are discussed. The application of the Bick method to research has achieved increasing recognition due to its potential for generating new ideas and for contributing to theoretical discussions in the area of developmental psychology, and especially in psychoanalysis.

Keywords: Bick method, research method, infant observation
\end{abstract}

O presente artigo representa uma possibilidade de discussão sobre o método Bick de observação de bebês como um método de pesquisa. Procuramos desenvolver uma descrição do método desde sua criação, buscando fazer uma aproximação com a prática clínica e com a pesquisa, através de seu potencial de gerar novas idéias e conceitos sobre o desenvolvimento infantil e a relação do bebê com seus cuidadores.

O método Bick foi criado em 1948, em Londres, por Esther Bick, visando prover experiência prática com bebês, e, desde então, tem sido incluído no currículo do curso de formação de psicoterapeutas da Clínica Tavistock, em Londres. Esther Bick foi pioneira ao criar um método que permite uma vivência prática nos primeiros anos de formação de psicoterapeutas infantis, servindo de auxílio para que os estudantes em formação possam compreender mais claramente a experiência infantil de seus pequenos pacientes. Dessa forma, ao começar o tratamento de uma criança de dois anos e meio, por exemplo, o analista pode intuir como era quando bebê. A experiência de observação é também útil para entender melhor a conduta não-verbal da criança e seus jogos, assim como a conduta da criança que não fala nem joga. Além disso, o método pode auxiliar o estudante que entrevista a mãe, para que compreenda as informações que esta lhe dá sobre a história da criança. O método Bick de observação oferece uma excelente oportunidade de observar o desenvolvimento de um bebê desde o nascimento, no ambiente da família e em sua relação com a família, acompanhando como se originam e desenvolvem tais relações. A partir das supervisões, o estudante poderá comparar e estabelecer diferenças entre suas próprias observações e as de seus colegas nos seminários semanais.

O bebê é observado no seu ambiente familiar. Neste sentido, Pérez-Sanchez (1983) questiona o uso do termo "Observação de bebê" (Infant Observation) para 
se referir ao método de observação proposto por Esther Bick. Segundo ele, o que se observa é uma família dentro da qual nasceu um bebê. É interessante, neste aspecto, que no Brasil o método seja conhecido como "Observação da relação mãe-bebê”, incorporando, portanto, o caráter relacional da observação.

O método tem sido cada vez mais reconhecido como um importante recurso para a formação de psicoterapeutas e psicanalistas infantis e, desde 1960, foi incluído no currículo do Instituto de Psicanálise em Londres (Bick, 1964/1987). No Brasil, o método atualmente integra o currículo oficial da formação de psicanalistas na Sociedade Brasileira de Psicanálise do Rio de Janeiro (Rosa, 1995). Na Sociedade Brasileira de Psicanálise de São Paulo, o método Bick de observação é obrigatório para o curso de formação de analistas de crianças e adolescentes e optativo para o curso de formação de analistas de adultos. No Rio Grande do Sul, o método compõe o currículo de formação de psicoterapeutas do Centro de Estudos, Atendimento e Psicoterapia na Infância e Adolescência (CEAPIA) e é oferecido, em caráter opcional, na Sociedade Psicanalítica de Porto Alegre.

Para Rustin (1989, 1997), além de ensinar como se observa, o propósito da observação de bebês através do método Bick é refletir sobre as interações entre o bebê, a mãe e os demais cuidadores. Esta metodologia permite que cada observador pense sobre o desenvolvimento do bebê e sobre sua relação com a mãe. Além disso, a regularidade das observações, as quais são realizadas no mesmo lugar e na mesma hora da semana, demarca um setting constante. O setting, por sua vez, denota o estreito vínculo com a Psicanálise, ou seja, atenção aos mínimos detalhes, observação do contexto, estudo da continuidade genética, tipo de contrato de trabalho, supervisão continuada - de preferência com psicanalista experiente compreensão dos conflitos e sentimentos com seus dinamismos.

O procedimento metodológico do método Bick é realizado em três tempos (observação, anotação e supervisão), o que, segundo Houzel (1997a), traduziria um dos postulados metapsicológicos fundamentais que explica o funcionamento psíquico e que funda o método de observação de bebês, isto é, a idéia de que o psiquismo é organizado em instâncias. Para o autor, a distribuição em três tempos é semelhante à apresentada por Freud em "Formulações sobre os dois princípios do funcionamento mental” (1911/1987). Assim, temos: 1) o tempo da observação, no qual o observador vai à casa do bebê uma vez por semana, permanece durante uma hora e mantém uma relação cordial e respeitosa; 2) o tempo das anotações, no qual o observador, após a visita, registra por escrito, procurando incluir todos os detalhes lembrados e, especialmente, os afetos por ele experimentados; e 3) o tempo da supervisão, ocasião na qual o observador pode compreender, organizar e dar sentido a estas vivências, podendo resgatar mais facilmente a 
sua função, ocorrendo semanalmente com o grupo de observação e o coordenador psicanalista.

O observador é orientado a participar da experiência, despindo-se, tanto quanto possível, dos seus hábitos terapêuticos e teorias que embasam o seu dia-adia clínico, para poder, então, tão somente observar. A palavra de ordem presente na descrição do método e seus achados por Bick é que partimos do não-saber: eu não sei e não procuro nenhuma conclusão. Nesse sentido, observar um bebê significa deixar-se impregnar por uma realidade sensível - sons, cores, atmosferas emocionais - que entram em ressonância com esses mesmos aspectos do observador. É relevante uma atitude de espera, tolerância e paciência frente ao desconhecido e ao "não saber". Significa deixar-se penetrar por mensagens não compreendidas, tolerar esta não-compreensão, suportar viver na falta de um sentido, aguardando que ele surja. Além disso, o observador deve ser discreto, atento, receptivo, delicado e não crítico, para depois relatar suas observações nos mínimos detalhes. Não deve aconselhar, interpretar, interferir. Esta capacidade de lidar com o não-saber é reconhecida como indispensável ao analista, em sua prática clínica, para poder acompanhar seu paciente sem precipitar interpretações.

O observador aprende a observar, a sentir antes de teorizar e tolerar, acompanhar as mães no cuidado com seu bebê, encontrando suas próprias soluções. Pode também aprender a estar com a mente aberta, sem idéias pré-concebidas e assim perceber a singularidade de cada relação mãe-bebê.

A supervisão é um aspecto do método que merece destaque. Segundo Souza (1995), ela se dirige a dois focos: aquilo que é observado (a dupla mãe-bebê) e o instrumento de observação (o observador). Ainda segundo a autora, a observação de bebê oferece uma oportunidade para o treinamento do analista, com o objetivo de torná-lo um "aparelho psicanalítico" de bom funcionamento. O observador observa o bebê e seu entorno, relatando inclusive as suas próprias reações, para, então, formular compreensões do que está ocorrendo.

A supervisão serve para aprimorar o "instrumento" observador, ajudando-o a refletir sobre o seu desempenho. O supervisor e o restante do grupo, através de associações livres e também através de uma escuta calcada na atenção flutuante, conduzem a supervisão no sentido de "iluminar o inconsciente" do observador, não somente permitindo que os dados que não foram relatados possam ser resgatados, mas também que os dados registrados sejam compreendidos (Souza, 1995). O relato do observador atinge o grupo de supervisão, permeando e contaminando seus participantes, que se distribuem em papéis e funções, num trabalho de decodificação das comunicações primitivas do texto. Como assinalado por Chiappini e Miyares (1997), o bebê transmite estados emocionais primitivos que 
devem ser transformados psiquicamente. O observador recebe, com sua emocionalidade, sua fantasia e até seu próprio corpo, as comunicações do bebê e seu entorno. Adquire uma visão binocular: observa o que se passa no exterior e se observa desde o interior. O grupo de supervisão ajuda a colocar em palavras essas comunicaçôes primitivas. Quando esse processo, sustentado pelo grupo, prossegue, surge um novo sentido, surpresas compartilhadas, inéditas, que sinalizam novas verdades psíquicas e possibilidades de acesso às mesmas.

Para Sandri (1997), a supervisão representa um espaço continente para as angústias primitivas que mobilizam o observador. A autora sugere que essa função continente seja semelhante à função de sustentação do pai e da família em relação à mãe. Neste sentido, o grupo de supervisão assume uma posição de terceiro, que possibilita a passagem do impacto emocional para um trabalho de elaboração psíquica. Tal espaço continente se faz necessário devido ao impacto sofrido pelo observador ao contatar o primitivo, aquilo que carece de simbólico. O observador precisa estar amparado em um grupo, uma vez que esse método de observação o coloca em contato com a sua própria realidade psíquica e a do bebê e seu entorno.

Os conceitos de atenção flutuante e transferência são fundamentais para o método Bick de observação. Em "Recomendações aos médicos que exercem a psicanálise”, Freud (1912) denominou de atenção flutuante o modo como o analista deve escutar o analisando. Consiste em o analista não privilegiar a priori qualquer elemento particular do discurso do analisando. Seria, portanto, o oposto da atenção focalizada. É esta regra que permite ao analista descobrir as conexôes inconscientes no discurso do paciente. Bick (1964/1987) destacou a importância de o observador não fazer anotações durante as observaçôes, de forma a não interferir na atenção flutuante, podendo responder mais facilmente às demandas emocionais da mãe.

Transferência é o processo pelo qual os desejos inconscientes se atualizam sobre determinados objetos no quadro de um certo tipo de relação estabelecida com eles e na relação analítica. É uma repetição e reatualização de protótipos de relacionamentos infantis não somente no setting terapêutico, mas em todas as relações (Laplanche e Pontalis, 1982/1992; Chemama, 1993). A postura receptiva do observador facilita a projeção do bebê e de seu entorno. Esta postura potencializa a constituição da relação transferencial, uma vez que promove a reprodução e atualização, na pessoa do observador, de padrōes de relaçôes infantis.

Ainda sobre a questão transferencial, Bick (1963/1987) fala da importância de se reconhecer a contratransferência. Sugere que o estresse associado à contratransferência no analista de crianças é maior do que em analistas de adultos, devido aos conflitos inconscientes que afloram na relação com os pais da criança e à 
natureza do material da criança - projeções violentas e concretas que tornam difícil a contenção. $\mathrm{O}$ material infantil é mais primitivo. Neste sentido, o método Bick seria uma importante alternativa de aprendizagem, uma vez que permite ao observador reconhecer e conter os sentimentos contratransferenciais através das supervisões.

Para Reid (1997), o que vemos, ao observar as relações humanas tão de perto, é comumente extraordinariamente comovente e bonito, mas pode ser também profundamente perturbador. Pode ser comparado a olhar as relações humanas num microscópio, focalizando os menores detalhes envolvidos em qualquer troca humana. Levar em consideração as percepções e as reações transferenciais ao observador parece ser uma pré-condição para o entendimento das situações familiares, assinala Rustin (1997).

Em um trabalho realizado por um grupo de observação de bebês supervisionado por uma das autoras do presente artigo (Caron, Matte, Cardoso, Lopes, Dalcin, 2000), ressaltou-se o quanto é impactante e violento o contato com o humano, com suas cruezas, incertezas, medos e ilusões/desilusões. O observador e o grupo entram em contato com tendências comuns, sentimentos de ambivalência, angústia e agressividade presentes no ser humano, mas em geral vivenciados como alheios ou estranhos, para utilizar uma expressão de Freud (1919). O medo de invadir é muito comum neste tipo de observação. No entanto, na sutileza e delicadeza do cotidiano, o observador é invadido e surpreendido pela violência de palavras, sensações e gestos ambivalentes, bem como pelos medos mais primitivos de solidão, escuridão e desamparo.

Bick (1964/1987), embora não tenha criado o método de observações pensando em sua aplicação terapêutica e na pesquisa, sugere que a observação beneficia as mães e seus bebês, ao mencionar que "muitas mães demonstraram explícita e implicitamente que estavam contentes de receber regularmente uma pessoa para poder falar sobre o bebê e seu desenvolvimento e sobre seus próprios sentimentos para com ele" (Bick, 1964/1987: 241). Nesse sentido, a observação abre um espaço no qual a mãe tem a possibilidade de se aliviar e descarregar, já que conta com um observador empático e não intrusivo.

Há um reconhecimento de que a mera presença dos observadores faz diferença para os bebês e suas famílias, o que leva a algumas reflexões sobre os possíveis usos práticos e preventivos do método de observação de bebês. $\mathrm{O}$ aspecto mais positivo da observação de bebês, do ponto de vista das famílias observadas, parece ser o fato de fornecer um "espaço reflexivo" (Rustin, 1997: 97) adicional para a mãe. O observador de bebê compartilha o espaço emocional da mãe e do bebê e se torna o recipiente de algumas das projeções que vão e vêm entre a mãe, 
o bebê e outros membros da família. Em algumas situações familiares difíceis ou quando o observador se torna o objeto particular destas projeçóes, esta experiência pode ser dolorosa. Mas parece haver pouca dúvida de que, com anotações cuidadosas e auto-análise, estes dados podem gerar insight sobre os estados mentais da mãe e do bebê, da mesma forma que sobre as "partes infantis" das mentes de pacientes adultos em psicoterapia (Idem: 105).

Caron (1995) destaca a função de observador que se inclui na formação profissional, em sua atitude, no interesse e conhecimento das capacidades dos bebês, na aptidão de poder contatá-los, bem como seus próprios aspectos infantis. É fundamental que o observador esteja identificado com a sua função, resguardando a origem e a configuração própria do método. Pode ser terapêutico o observador incluir-se na observação de uma forma não agente, mas vivenciada. Apoiado na premissa de Bion de que a mãe ou o terapeuta funcionam como "continente" para a atividade mental do bebê e do paciente, Stern (1995/1997) também aponta o caráter terapêutico da observação pelo Método Bick. Winnicott (1971/1975) desenvolve o conceito de holding como uma função de sustentação, que deve estar presente na mãe suficientemente boa e que poderíamos dizer que integra também o papel do observador, uma vez que ele cria uma atmosfera de sustentação da relação do bebê com seus cuidadores.

O método Bick de observação efetivamente promove uma abertura aos aspectos não-verbais da comunicação, trazendo inúmeras contribuições para a formação do psicanalista ou psicoterapeuta de crianças. Os benefícios não são traduzidos somente em mudanças na maneira de trabalhar, pensar e compreender seus pacientes, mas também como uma possibilidade de crescimento pessoal, na medida em que novos projetos profissionais e novas aberturas na prática clínica com acesso a novas vias de reflexão tendem a ocorrer.

Uma vez situados os principais pressupostos teóricos do método, passamos, a seguir, a destacar o seu potencial como método de pesquisa do desenvolvimento do bebê no seu ambiente.

\section{APLICAÇÃO DO MÉTODO NA PESQUISA}

Bick (1964/1987) considerava a observação de bebês uma excelente oportunidade de observar o desenvolvimento do bebê, desde o nascimento, na casa, na sua relação com a família, e descobrir como se originam e se desenvolvem tais relações ao longo dos dois primeiros anos de vida do bebê. Apesar de o método ter sido originalmente proposto com o intuito de auxiliar a formação de psicoterapeutas, acredita-se no seu potencial como instrumento de pesquisa, o 
qual, segundo Rustin (1997), pesquisador da Clinica de Tavistock e defensor da aplicação do método na pesquisa, ainda não foi devidamente descoberto. Na mesma direção, Reid (1997), também pesquisadora da Clínica de Tavistock e defensora da aplicação do método na pesquisa, aponta que, apesar de as observações serem feitas como parte de uma formação de psicoterapeutas, elas também constituem uma base de dados significativa para fins de pesquisa. A própria Bick (1961/ 1987) deixou implícito o potencial do método para a pesquisa, ao considerar a possibilidade de a observação ajudar a compreender mais claramente a experiência infantil nos primeiros anos de vida, bem como ao destacar a sua utilidade para compreender melhor a conduta não-verbal da criança que não fala e não joga. $\mathrm{O}$ fato de o trabalho de observação passar por um grupo de supervisão permite, também, a possibilidade de comparar e distinguir diferentes casos de observação.

São recentes as tentativas de promover um diálogo do método com a pesquisa científica (Caron, 1995; Caron e Lopes, 2001; Rosa, 1995; Rustin, 1997; Reid, 1997), que têm sido impulsionadas, principalmente, pelo valor atribuído aos relatos de observação. Muitos observadores foram percebendo o potencial das contribuições dos relatos de observação para a pesquisa psicanalítica. $\mathrm{O}$ método Bick de observação deixou, então, de ser visto somente como auxiliar na formação de psicoterapeutas e psicanalistas infantis, passando a ser enfatizado o seu potencial como fonte de dados, na medida em que, valendo-se dos materiais apresentados na supervisão, podemos contribuir com a teoria psicanalítica, fazendo-a avançar em conceitos sobre o desenvolvimento infantil e sobre a relação entre o bebê e seus cuidadores. A própria idealizadora desse método criou a sua teoria sobre a função primordial da pele no bebê em relações objetais precoces, discutindo o desenvolvimento de uma "segunda pele", em situações psicopatológicas, a partir da observação de bebês. $\mathrm{O}$ artigo "The experience of the skin in early object relations", é um exemplo clássico de descoberta psicanalítica a partir da observação de bebês (Bick, 1968/1987).

$\mathrm{O}$ crescente interesse no material proveniente das observações vem se manifestando, por exemplo, nos Congressos Internacionais organizados especificamente com o objetivo de reunir trabalhos baseados no método Bick de observação. Até o presente momento, já foram organizados sete eventos específicos voltados ao método Bick de observação. Inicialmente, tais eventos eram chamados de Colóquios, por serem mais regionais, e posteriormente foram denominados como Congressos Internacionais, em função de sua abrangência. Os sete eventos são: $1^{\circ}$ Colóquio Europeu sobre a observação dos lactentes, em 1991, na cidade de Bruxelas; 20 Colóquio Europeu, em 1993, na cidade de Toulouse; 30 Colóquio Internacional, em 1996, na cidade de Barcelona; IV $^{\circ}$ 
Congresso Internacional de observação de bebês - Método Bick, em 1998, na cidade de Lisboa; $V^{\circ}$ Congresso Internacional de observação de bebês, em 2000, na cidade do Rio de Janeiro; $\mathrm{VI}^{\circ}$ Congresso Internacional sobre o método de observação de Esther Bick, em 2002, na Cracóvia; VII ${ }^{a}$ Conferência Internacional sobre observação de bebês em 2004, na cidade de Florença. Além disso, ocorreram outros eventos menores, mas não menos importantes, como a Conferência sobre observação de bebês, em 1993, na Clínica Tavistock, em Londres; o Primeiro Simpósio Brasileiro sobre observação da relação mãe/bebê-família, organizado pela Sociedade Psicanalítica de São Paulo, em 1995; o Segundo Simpósio Brasileiro de observação da relação mãe-bebê, em 1997, na cidade de Gramado. A aplicação do método Bick na pesquisa tem merecido espaços específicos de discussão nesses eventos. Destacamos os últimos eventos ocorridos em 1997, em Gramado, em 2002, na Cracóvia, e em 2004, em Florença, que abriram espaços de discussão sobre o método Bick de observação e a pesquisa. Outro aspecto que dá respaldo ao crescente interesse pelo método como fonte de dados científicos sobre o desenvolvimento infantil foi a criação, em 1997, de um periódico, Journal of Infant Observation, da Clínica Tavistock, com publicações baseadas em material de observação de bebês. No editorial do primeiro número encontramos uma afirmação que pode referendar a importância da observação de bebês como fonte de achados científicos sobre o início da vida: "a observação sensível e exata dos bebês e crianças pequenas pode trazer insights previamente menosprezados em disciplinas que agora abrigam o acréscimo de cor, imaginação e emocionalidade, sem perder o rigor intelectual e a clareza da estrutura" (Journal of Infant Observation, 1997, Editorial: 5).

Cada bebê observado pode ser considerado como um estudo de caso (Reid, 1997; Rustin, 1989). O estudo de caso proveniente da observação de bebês seria uma excelente ferramenta de pesquisa, e a própria observação de bebês pode ser reconhecida como equivalente a estudos de casos psicanalíticos em seu potencial de gerar novas idéias e influenciar a técnica clínica. Há também a possibilidade de cotejar resultados da observação através do método Bick com pesquisas realizadas com outras metodologias, reconhecendo que nenhum método de pesquisa é suficiente para estudar um determinado objeto.

A observação pelo método Bick é um recurso para gerar novas idéias e entendimentos em psicanálise, mas, como todo método, apresenta limitações. Não é passível de generalizaçóes dos resultados, a partir de instâncias individuais. Se, por um lado, o estudo de poucos casos impede o tratamento estatístico, por outro permite o aprofundamento qualitativo de cada caso, na medida em que possibilita a descrição de condutas diretamente observáveis em detalhes (Rustin, 2001). 
Para Reid (1997), “os achados dos estudos baseados na observação de bebês têm servido de base para uma ampla gama de projetos de pesquisa clínicos, têm influenciado a prática clínica e têm trazido contribuições para o pensamento psicanalítico" (Reid, 1997: 52). A autora continua: "as descrições próximas e detalhadas do desenvolvimento do bebê, ao longo de um período de dois anos, propiciadas por estas observaçóes psicanalíticas de bebês, complementam as informaçōes geradas por pesquisas em laboratório, nas quais foram desenvolvidas metodologias que permitem observações padronizadas com um número grande de bebês" (Reid, 1997: 52). Diferentemente de investigações de interações mãebebê no laboratório, o comportamento da mãe e do bebê não é previsto ou prescrito. Apesar de difícil de ser quantificado, o material não é contaminado por nenhum tipo de busca por evidência para apoiar determinada hipótese. Sendo assim, o material, uma narrativa do desenvolvimento de um bebê, pode ser tomado como dado de pesquisa "puro". A autora conclui que o estudo de caso baseado na observação de bebês tem sido pouco valorizado como instrumento de pesquisa.

Apesar de o método de observação ser aberto e não organizado em protocolos, medidas ou convenções, é, contudo, consistente na sua abordagem. Como outros autores (ex. Houzel, 1997a), Rustin (1997) também defende a idéia de que o enquadre tem similaridades com o da psicanálise clínica. A insistência em um setting observacional confiável e consistente busca servir aos mesmos propósitos na análise clínica e na observação de bebês. Em ambos os casos, seus aspectos constantes tornam possível aos terapeutas analíticos e aos observadores de bebês identificar variações significativas no que observam e refletir sobre as possíveis causas e implicaçóes destas variaçóes.

Do ponto de vista científico, o princípio central do método Bick é a primazia da descoberta em relação à explicação, conforme assinala Briggs (2004). Bick não se interessava em oferecer explicações antes de ver um padrão emergir. Ensinou-nos a ter cautela e a nos apoiar em observaçóes consecutivas para confirmação (Bick, 1964/1987). Os observadores aprendem a sentir e observar, a tolerar e apreciar o modo como as mães cuidam dos seus bebês - a unicidade de cada dupla, como cada bebê se desenvolve no seu próprio ritmo e se relaciona de um modo próprio com a mãe. Segundo Briggs (2004), o uso deste método de observação contrasta com o uso da observação discutido por outros autores psicanalíticos, como, por exemplo, Anna Freud: teste de hipóteses ou busca de evidências para confirmar a existência de certos aspectos estruturais ou dinâmicos do psiquismo da criança. O cerne do método é, conforme Briggs, a atenção ao detalhe externo e ao interno. 
Esta atitude não especulativa do observador encontra apoio em Freud (1914), quando trabalhava na descoberta do inconsciente. Nas palavras de Freud: "Aprendi a controlar as tendências especulativas e a seguir o conselho, não esquecido, do meu mestre Charcot: olhar as mesmas coisas, repetidas vezes, até que elas comecem a falar por si mesmas" (Freud, 1914: 32).

Alguns benefícios da observação, como treinamento para coleta de dados científicos e para o desenvolvimento do pensamento científico, são salientados por Bick (1964/1987). Desde o início, percebe-se o quão difícil é "observar”, i.e., coletar fatos isentos de interpretação. Tão logo estes fatos têm que ser descritos em linguagem, percebe-se a dificuldade, porque pensamento e linguagem são quase inseparáveis. Para Briggs (2004), Bick tinha uma suspeita em relação às palavras, que poderiam obscurecer as coisas da visão e fazer perder a oportunidade de ver algo se desenvolvendo.

A atenção flutuante do observador simula a do analista observando o seu paciente. Freud (1912) aconselhava: "o médico deve voltar seu próprio inconsciente, como órgão receptor, na direção do inconsciente transmissor do paciente" (Freud, 1912: 154), afirmando ainda, em 1915: "constitui fato marcante que o inconsciente de um ser humano possa reagir ao de outro sem passar através do consciente" (Freud, 1915: 222). Pensando na aplicação do método na pesquisa, Briggs (2004) defende a utilização da mesma postura de atenção flutuante. O pesquisador não pode ter hipóteses prévias.

Alguns relatos de observação pelo método Bick tornaram-se fonte de publicação de artigos, por trazerem contribuições relevantes para a teoria psicanalítica e a psicologia do desenvolvimento. Podemos citar estudos sobre o desenvolvimento de estar separado e individualizado (Lisa Miller, 2002), o caráter terapêutico do método Bick de observação (Lynda Miller, 2002), a dificuldade de um bebê manter contato visual (Cowsill, 2000), o desenvolvimento de características autísticas em um bebê (Somerville, 2000), ou a emergência e gênese da violência (Monmayrant e Lacroix, 1997). Tais estudos foram provenientes do uso do método Bick de observação como ele originalmente foi proposto.

Outra área em que a observação de bebês tem se mostrado teoricamente fértil é a investigação de estágios precoces do desenvolvimento, como, por exemplo, o trabalho pioneiro de Piontelli (1992/1995). Trata-se do primeiro estudo longitudinal de orientação psicanalítica que incluiu em seu delineamento o período pré-natal. Foram observados 11 fetos (três gestações singulares e quatro pares de gêmeos), através de imagens de ultrassonografia, a partir da décima sexta semana de gestação, mensalmente. Após o nascimento, utilizando o método Bick de observação da relação mãe-bebê, foram realizadas semanalmente observações do- 
miciliares até a idade de dois anos do bebê. A partir dos dois anos, as observações ocorreram três vezes ao ano, até a idade de quatro anos. Piontelli (1992/1995) combina aspectos do desenvolvimento comportamental do feto, etologia e psicanálise. Considera seu achado central a existência de uma notável continuidade de comportamento antes e depois do nascimento e sugere que certas experiências pré-natais podem ter efeito emocional profundo sobre a criança, especialmente se tais acontecimentos forem reforçados pelas experiências pós-natais.

Atualmente, o método Bick de observação está sendo aplicado numa pesquisa com um delineamento longitudinal, que, como o estudo de Piontelli (1992/ 1995), tem início no período pré-natal (Caron e Lopes, 2001). Participaram do estudo sete bebês e seus cuidadores, que foram observados no período pré-natal e após o nascimento, até completarem três anos de vida. A pesquisa encontra-se, atualmente, em fase de análise dos dados.

O método Bick de observação tem muitas aplicações potenciais e atuais, em âmbitos da saúde, educação e no social. Alguns trabalhos vêm se destacando pelo fato de se inserirem num contexto institucional, no qual a observação é aplicada em outro tipo de setting, com características diferentes daquelas que fazem parte da observação tradicional de bebês. Por exemplo, no contexto hospitalar, Druon (1997) desenvolveu um estudo trabalhando no limite da vida fetal e da vida exterior, em casos de bebês que eram encaminhados para a UTI Neonatal e que tinham que ficar em incubadoras. Neste caso, o método Bick teve que ser adaptado à realidade da UTI Neonatal, envolvendo mudanças na freqüência e na duração das observações. Baseado no trabalho de Druon (1997), Wirth (2000) desenvolveu, em Porto Alegre, um trabalho de acompanhamento de bebês prematuros e seus pais na UTI neonatal. Cresti e Lapi (1997) também realizaram uma aplicação do método Bick no contexto hospitalar, observando a interação do bebê com a mãe e com o ambiente hospitalar. Mais recentemente, ainda no contexto hospitalar, está sendo realizada, em Porto Alegre, uma tese de doutorado baseada no acompanhamento de parturientes na sala de parto (Donelli, 2005).

Outro trabalho de observação pelo método Bick que se inscreve em um trabalho institucional é o de Appell (1997), cuja observação ocorreu numa instituição que abriga crianças, levando a instituição como um todo a desenvolver uma postura observante, trazendo benefícios para as crianças e para toda equipe. Jardin, Detry, Denis, Moreau e Silbermann (1997) apresentam a experiência de empregar o método Bick de observação em duas instituições: a creche e o setor de Psiquiatria Infantil, contando com uma equipe multidisciplinar que visa o cuidado precoce da criança pequena e o apoio da função parental. A proposta é a de que há a possibilidade de se fazer a observação como meio terapêutico dentro da creche. 
A observação de bebês em situações atípicas tem sido outra área de pesquisa desenvolvida por alguns autores, ressaltando-se o caráter terapêutico do método. Por exemplo, Houzel (1997b, 1999) aplicou o método Bick de observação no tratamento de desordens funcionais severas da primeira infância, tais como transtornos do sono e da alimentação, autismo e psicose infantil. $\mathrm{O}$ autor propunha aplicar a observação nos dois primeiros anos para então associar a observação à psicoterapia individual com a criança. Famílias atípicas também foram objeto de estudo de Reid (1997), que observou crianças autistas e mostrou o desenvolvimento precoce de defesas autistas. Em Porto Alegre, está sendo desenvolvida uma tese de doutorado, por uma das autoras do presente artigo, que consiste na aplicação do método na observação de uma família de um bebê portador de síndrome de Down (Oliveira, 2004). Caron e Maltz (1994) também aplicaram o método Bick de observação em situações atípicas, através de observações de grávidas que receberam diagnóstico ecográfico de malformação congênita. Conforme a necessidade, as observações eram realizadas na clínica, no hospital, nas casas, durante o período pré-natal, tendo continuidade no parto e pós-parto. Outros autores como Rajon, Rosé e Abadie (1997) aplicaram o método Bick de observação ao contexto do diagnóstico perinatal de malformação congênita, o que os levou a considerar as funções terapêuticas da observação.

O método vem sendo aplicado também em pesquisas em diferentes contextos sociais. Em Porto Alegre, está sendo desenvolvida uma dissertação de mestrado que consiste na aplicação do método numa pesquisa com famílias de baixa renda. O foco é o desenvolvimento emocional de uma criança em uma família numerosa (Vivian, 2005).

\section{Aspectos éticos do MÉTOdo BICK APLICAdo À PESQUiSA}

Para discutir os aspectos éticos do método de observação criado por Esther Bick e sua aplicação à pesquisa, tomaremos a resolução do Conselho Federal de Psicologia $N^{\circ}$ 016/2000 de 20 de dezembro de 2000, que dispõe sobre a realização de pesquisa em Psicologia com seres humanos. Este documento abrange três eixos principais, que são: o risco da pesquisa, o consentimento informado e a confiabilidade, sigilo e uso de informações.

No que se refere ao risco da pesquisa, a resolução prevê que é obrigação do pesquisador avaliar os riscos envolvidos, a fim de proteger os participantes de pesquisa. Isso implica que o pesquisador deve dispor de recursos para lidar com as possíveis conseqüências de seus procedimentos, intervindo, imediatamente, sempre que houver a possibilidade de algum dano. No caso do método Bick, acredi- 
tamos que esta questão fica assegurada pela supervisão, que auxilia o observador a manter-se na sua função. A supervisão permite ao observador exercer uma influência benéfica e facilitadora na interação mãe-bebê (Mélega, 1997). Ela opera como contenção do observador. Por isso, é importante que a supervisão seja conduzida por um psicanalista clínico e observador experiente. É o trabalho de supervisão que dará sustentação ao observador no momento da observação.

Outro aspecto enfatizado neste item refere-se à proteção dos participantes, sempre que constatado que estes se encontram em situação de risco iminente a sua integridade física ou emocional. Trata-se da proposta de intervenção do pesquisador, quando esta se faz necessária. Neste sentido, a resolução 196/96 do Conselho Nacional de Saúde de 14 de janeiro de 1987 igualmente dispõe sobre pesquisa com seres humanos e prevê que toda pesquisa envolve risco. Apesar destes riscos potenciais, estas pesquisas são admissíveis quando oferecem elevada possibilidade de gerar conhecimento, para entender, prevenir ou aliviar um problema que afete o bem-estar dos indivíduos. Além disso, o risco deve se justificar pela importância do benefício esperado, o qual deve ser maior ou igual a outras alternativas já estabelecidas para a prevenção, o diagnóstico e o tratamento.

No que se refere à proteção dos participantes, acreditamos que, assim como acontece com o método Bick de observação em sua versão original, em sua aplicação à pesquisa não há uma neutralidade no observador. Desta forma, não poderíamos pensar em um observador que se coloca fora da cena que está sendo observada e que não protege os indivíduos observados com sua presença. Caron (1995) destaca, nesse sentido, que "o observador desempenha uma efetiva participação não-verbalizada, não agente, mas vivenciada, ou seja, o observador inclui-se no processo acompanhado" (Caron, 1995: 283). Mélega (1997) sustenta opinião semelhante ao afirmar que "Bick estabeleceu um enquadre em que o observador se coloca de maneira a não causar grandes perturbaçôes no meio familiar pela sua presença e, ao mesmo tempo, permanecer no campo emocional da família” (Mélega, 1997: 749). Rosa (1995) também reconhece que o método Bick de observação tem a pretensão de ser o mais natural possível, buscando preservar o ambiente familiar, embora se saiba que a simples presença do observador influencia e modifica o ambiente. O observador deve incluir-se na observação, sendo a ele endereçadas mensagens verbais ou não, emoções, sofrimento, desejos, medos.

Também para Rustin (1989), o observador deve ser receptivo ao que ocorre na observação. Ele é um participante inevitável, tendo um papel não interventivo, como nos métodos etnográficos das ciências sociais. As principais qualidades exigidas dos observadores deste método são sensibilidade e capacidade de pensar 
sobre sentimentos. Eles somente podem entender a relação central entre a mãe e o bebê, se forem capazes de experenciar alguns dos impactos do bebê na mãe.

O observador, ainda segundo Rustin (1997), deve prover atenção à mãe e ao seu bebê, sem fazer demandas explícitas a ela, mesmo que seja de uma informação. O interesse e os pensamentos da mãe sobre o bebê são apreciados e não julgados. O observador deve ser reconhecido pela sua presença não intrusiva e continente.

Com relação ao consentimento informado, pensamos que a aplicação do método Bick de observação à pesquisa também está de acordo com o que a resolução prevê, na medida em que este envolve o respeito à autonomia, liberdade e privacidade dos indivíduos. Dentro disso, o método é aplicado a partir da participação voluntária dos participantes, sendo que os mesmos são informados sobre os objetivos da pesquisa e sobre os procedimentos aos quais serão submetidos.

Por fim, no que se refere à confiabilidade, sigilo e uso de informações, acreditamos que o método também corresponde ao previsto pela resolução do Conselho Federal de Psicologia Nº16/2000 de 20 de dezembro de 2000. No método Bick de observação e em sua aplicação à pesquisa, os dados observados são relatados ao grupo de supervisão pelo observador. $\mathrm{O}$ grupo de supervisão consiste no supervisor e demais observadores, que se comprometem a conservar o sigilo das informações obtidas na pesquisa, além de acompanhar e conter o observador, evitando que comprometa a sua ética, enquanto observador.

Com relação ao sigilo, percebem-se algumas similaridades do método de observação desenvolvido por Bick com a clínica psicanalítica, até porque a criadora do método é psicanalista. Há uma insistência na confiança e consistência do setting observacional, para servir a alguns dos mesmos propósitos da psicanálise e da observação de bebês. Em ambos os casos, a característica constante faz com que seja possível para o psicanalista ou observador identificar variações naquilo que eles observam, permitindo a reflexão sobre as possíveis causas e implicações destas variações (Rustin, 1997).

Para o método Bick de observação, o requisito central para o observador é manter-se em sua posição de observador. Assim, não deve emitir julgamentos morais e críticas e deve respeitar o desenvolvimento do vínculo com seus cuidadores. Desta forma, o observador vai poder acompanhar a constituição desses laços sem interferir ou impedir o desenvolvimento dos mesmos. Isso não significa que não haja uma intervenção, na medida em que o observador é um elemento a mais no sistema, mas essa intervenção não pode ter um caráter de interferência, de intrusão.

Observar é uma forma de intervenção que auxilia as famílias, uma vez que o observador se faz continente e receptáculo das angústias, dos medos e das sensações que fazem parte da cena da observação. Como a própria Bick (1964/1987) 
ressaltou, as mães em geral indicam, explícita ou implicitamente, como ficam satisfeitas com o fato de terem alguém regularmente em suas casas, com quem podem falar sobre o seu bebê, o seu desenvolvimento e seus sentimentos. $\mathrm{Na}$ realidade, é notável o quanto, em geral, não há dificuldade alguma em encontrar mães que aceitem ser observadas juntamente com os seus bebês, o que mais uma vez confirma o quanto as famílias se beneficiam deste método de observação.

\section{CONSIDERAÇỐES FINAIS}

Embora Esther Bick não tenha publicado muitos estudos, o método de observação por ela criado tem conquistado, ao longo do tempo, reconhecimento e cada vez mais está sendo aplicado à pesquisa, em função de seu potencial de gerar novas idéias e contribuir com discussões teóricas no âmbito da Psicologia do Desenvolvimento e da Psicanálise. O método que, inicialmente, foi criado para auxiliar na formação psicanalítica, pouco a pouco vem se mostrando favorável como método de pesquisa. Os relatos de observação passaram a ser considerados dados de pesquisa, por conta de seu potencial para gerar novas contribuiçôes teóricas. Ademais, o ponto forte desse método é a possibilidade de o observador/pesquisador acompanhar o desenvolvimento de um bebê, através de observações regulares. $\mathrm{O}$ setting estabelecido a partir do método permite a observação de minúcias no desenvolvimento do bebê e no estabelecimento de laços entre o bebê e seu entorno.

O observador faz parte da cena observada, já que sua simples presença gera uma mudança no ambiente, mas ele não deve interferir na emergência dos comportamentos do bebê e de seu entorno. O observador deve estar aberto para poder captar tais comportamentos detalhadamente e receber projeçóes e emoçóes que a ele são endereçados. Essa postura de receber e de fazer a contenção de emoções, que muitas vezes expressam sofrimento, tem chamado a atenção de alguns observadores e pesquisadores para o valor terapêutico desse método, o que aponta para contribuições não somente dirigidas à pesquisa, mas também à clínica. Estudos que priorizem a interface entre a clínica e a pesquisa são de suma importância para o desenvolvimento e reconhecimento cada vez maior desse método.

No âmbito da pesquisa, não podemos deixar de considerar a questão da ética. $\mathrm{O}$ método Bick de observação contempla os pressupostos da ética na pesquisa, na medida em que resguarda a integridade dos participantes da pesquisa, dando-lhes a liberdade e autonomia de participar do estudo, através do uso do consentimento livre e esclarecido. Além disso, a postura não intrusiva e receptiva do observador permite que o bebê possa se desenvolver dentro das peculiaridades da família onde está inserido. Interferências do observador na constituição de 
vínculos entre o bebê e seu entorno podem representar rupturas de tais vínculos. Por isso, a necessidade de um observador que permaneça numa posição observante e não intervencionista.

Acreditamos na aplicabilidade do método Bick de observação na pesquisa, desde que sejam respeitados os princípios do método, tais quais: atenção flutuante do observador e transferência. Os três tempos da observação (observação, anotação e supervisão) também devem ser respeitados, com ênfase no tempo da supervisão, pois é a partir da supervisão que o observador recebe contenção, o que lhe permite manter a sua função de observador, além de ser um espaço para trabalhar o dado da observação e os sentimentos despertados naquele que observa.

\section{REFERÊNCIAS BIBLIOGRÁFICAS}

Appell, G. (1997). Que tipo de observação usar para acompanhar uma criança pequena em coletividade. Em Lacroix, M. B. e Monmayrant, M. (Orgs.). Os laços do encantamento: a observação de bebês, segundo Esther Bick, e suas aplicações (pp. 79-85). (F. F. Settineri, Trad.). Porto Alegre: Artes Médicas.

Bick, E. (1961). Child analysis today. Em Harris, M. e Bick, E. (Orgs.). Collected papers of Martha Harris and Esther Bick (pp. 104-113). Great Britain: The Roland Harris Education Trust, 1987.

(1964). Notes on infant observation in psycho-analytic training. Em Harris, M.

e Bick, E. Collected papers of Martha Harris and Esther Bick (pp. 240-256). Great Britain: The Roland Harris Education Trust, 1987.

Bick, E. (1968). The experience of skin in early object relations. Em Harris, M. e Bick, E. Collected papers of Martha Harris and Esther Bick (pp. 114-118). Great Britain: The Roland Harris Education Trust, 1987.

Briggs, A. (2004). A stroke of genius: the uniqueness of Esther Bick's method. Trabalho apresentado na VII Conferência Internacional sobre Observação de Bebês. Florença, Itália.

Caron, N. A. (1995). Fundamentos teóricos para a aplicação do Método de E. Bick. Revista Brasileira de Psicanálise, 29 (2), 283-291.

Caron, N. A. e Maltz, R. S. (1994). Intervenção em gestantes com anomalias fetais. Revista de Psiquiatria da Sociedade de Psiquiatria do Rio Grande do Sul, 16, 202-207.

Caron, N. A. e Lopes, R. C. S. (2001). Estudo longitudinal sobre o desenvolvimento do bebê, da mãe e da relação mãe-bebê intra-útero e nos primeiros 3 anos de vida do bebê. Projeto não publicado. 
Caron, N. A.; Matte, L. D. S.; Cardoso, M. G.; Lopes, R. C. S. e Dalcin, V. E. (2000). Vivenciando a violência sutil: o impacto emocional diante de tendências humanas comuns. Em Caron, N. A. (Org.). A relação pais-bebê: da observação à clínica (pp. 45-60). São Paulo: Casa do Psicólogo.

Chemama, R. (Org.). (1993). Dicionário de psicanálise. (F. F. Settineri, Trad.). Porto Alegre: Artes Médicas, 1995.

Chiappini, C. H. e Miyares, A. R. (1997). Observación de lactantes: signos de alarma en el primer año de vida. Buenos Aires: Ediciones Kargieman.

Cowsill, K. (2000). "I thought you knew": some factors affecting a baby's capacity to maintain eye contact. The International Journal of Infant Observation, 3 (3), 64-83.

Cresti, L. e Lapi, I. (1997). O esboço da relação mãe-bebê e a instituição hospitalar: díade ou tríade. Em M. B. Lacroix e M. Monmayrant (Orgs.). Os laços do encantamento: a observação de bebês, segundo Esther Bick, e suas aplicações (pp. 149-162). (F. F. Settineri, Trad.). Porto Alegre: Artes Médicas.

Donelli, T. S. (2005). O parto e o tornar-se mãe: aplicação do método Bick de observação da relação mãe-bebê. Projeto de Tese de Doutorado não publicado, Programa de Pós-Graduação em Psicologia do Desenvolvimento, Universidade Federal do Rio Grande do Sul. Porto Alegre, RS.

Druon, C. (1997). Como o espírito vem ao corpo das crianças em UTI Neonatal. Em Lacroix, M. B. e Monmayrant, M. (Orgs.). Os laços do encantamento: a observação de bebês, segundo Esther Bick, e suas aplicaçôes (pp. 139-148). (F. F. Settineri, Trad.). Porto Alegre: Artes Médicas.

Freud, S. (1911). Formulações sobre os dois princípios do funcionamento mental. Em Obras psicológicas completas de Sigmund Freud, vol. XII. (J. Salomão, Trad.). Rio de Janeiro: Imago, 1987.

(1912). Recomendações aos médicos que exercem a psicanálise. Em Obras psicológicas completas de Sigmund Freud, vol. XII. (J. Salomão, Trad.). Rio de Janeiro: Imago, 1987.

. (1914). História do movimento psicanalítico. Em Obras psicológicas completas de Sigmund Freud, vol. XII. (J. Salomão, Trad.). Rio de Janeiro: Imago, 1987.

. (1915). Inconsciente. Em Obras psicológicas completas de Sigmund Freud, vol. XIV. (J. Salomão, Trad.). Rio de Janeiro: Imago, 1987.

(1919). O estranho. Em Obras psicológicas completas de Sigmund Freud, vol. XVII. (J. Salomão, Trad.). Rio de Janeiro: Imago, 1987.

Houzel, D. (1997a). Observação de bebês e psicanálise, ponto de vista epistemológico. Em Lacroix, M. B. e Monmayrant, M. (Orgs.). Os laços do encantamento: a observação de bebês, segundo Esther Bick, e suas aplicaçôes (pp. 87-94). (F. F. Settineri, Trad.). Porto Alegre: Artes Médicas. 
Houzel, D. (1997b). Uma aplicação terapêutica da observação dos lactentes. Em Lacroix, M. B. e Monmayrant, M. (Orgs.). Os laços do encantamento: a observação de bebês, segundo Esther Bick, e suas aplicações (pp. 193-207). (F. F. Settineri, Trad.). Porto Alegre: Artes Médicas.

Houzel, D. (1999). A therapeutic application of infant observation in child psychiatry. The International Journal of Infant Observation, 2 (3), 42-53.

Jardin, F.; Detry, L.; Denis, P.; Moreau, A. e Silbermann, A. (1997). A observação do bebê na creche. Em Lacroix, M. B. e Monmayrant, M. (Orgs.). Os laços do encantamento: a observação de bebês, segundo Esther Bick, e suas aplicaçōes (pp. 163-173). (F. F. Settineri, Trad.). Porto Alegre: Artes Médicas.

Laplanche, L. e Pontalis, J. B. (1982). Vocabulário de Psicanálise. (P. Tamen, Trad.). São Paulo: Martins Fontes, 1992.

Mélega, M. P. (1997). Pesquisa da atividade simbólica com ênfase no estudo do brincar: método de observação mãe-bebê Esther Bick. Revista Brasileira de Psicanálise, 31 (3), 745-760.

Miller, Lisa (2002). Lessons from infant observation: the developing mind of the infant. The International Journal of Infant Observation, 5 (1), 21-35.

Miller, Lynda. (2002). The relevance of observation skills to the work discussion seminar. The International Journal of Infant Observation, 5 (1), 55-73.

Monmayrant, M. e Lacroix, M. B. (1997). Observação do lactente e violência na criança pequena. Em Lacroix, M. B. e Monmayrant, M. (Orgs.). Os laços do encantamento: a observação de bebês segundo Esther Bick, e suas aplicaçôes (pp. 209-223). (F .F. Settineri, Trad.). Porto Alegre: Artes Médicas.

Oliveira, L. M. (2004). A relação mãe e bebê com Síndrome de Down: aplicação do método Bick de observação da relação mãe-bebê. Projeto de Tese de Doutorado não publicado, Curso de Pós-graduação em Psicologia do Desenvolvimento, Universidade Federal do Rio Grande do Sul. Porto Alegre, RS.

Pérez-Sanchez, M. (1983). Observação de bebês: relações emocionais no primeiro ano de vida. (Tânia Pellegrini, Trad.). Rio de Janeiro: Paz e Terra.

Piontelli, A. (1992). De feto a criança: um estudo observacional e psicanalitico. (J. Wilheim, N. L. Gomes, S. M. de Godoy, Trads.). Rio de Janeiro: Imago, 1995.

Rajon, A.; Rosé, D. e Abadie, I. (1997). Observação do lactente e atendimento terapêutico do par mãe-filho, no contexto do diagnóstico perinatal de malformação. Em Lacroix, M. B. e Monmayrant, M. (Orgs.). Os laços do encantamento: a observação de bebês, segundo Esther Bick, e suas aplicaçôes (pp. 225-231). (F. F. Settineri, Trad.). Porto Alegre: Artes Médicas.

Reid, S. (1997). The development of autistic defenses in an infant: the use of a single case study for research. Infant Observation: The International Journal of Infant Observation and its Applications, 1 (1), 51-110. 
Rosa, J. C. (1995). Reflexões sobre o método da observação da relação mãe-bebê. Revista Brasileira de Psicanálise, 29 (2), 299-305.

Rustin, M. (1989). Observing infants: reflections on methods. Em Miller, L.; Rustin, M. E.; Rustin, M. J. e Shuttleworth, J. (Eds). Closely Observed Infants (pp. 52-75). London: Duckworth.

. (1997). What do we see in the nursery? Infant observation as "laboratory work". Infant Observation: The International Journal of Infant Observation and its Applications, 1 (1), 93-110.

. (2001). Looking in the right place: complexity theory, psychoanalysis and infant observation. Lecture presented at a conference on "Origins and Evolution: the interplay o attachment theory and british objects relations”, at the Under Fives Study Centre. University of Virginia, Charlottesville, April 5-8, 2001.

Sandri, R. (1997). O grupo de observação: escuta, rêverie, transformação. Em Lacroix, M. B. e Monmayrant, M. (Orgs.). Os laços do encantamento: a observação de bebês, segundo Esther Bick, e suas aplicações (pp. 63-77). (F. F. Settineri, Trad.). Porto Alegre: Artes Médicas.

Somerville, G. (2000). "Everybody's dead": the observation of an infant with autistic features. The International Journal of Infant Observation, 3 (3), 39-63.

Souza, M. S. I. (1995). Supervisão da observação da relação mãe-bebê. Revista Brasileira de Psicanálise, 29 (2), 293-298.

Stern, D. N. (1995). A constelação da maternidade: o panorama da psicoterapia pais/bebê (M. A. V. Veronese, Trad.). Porto Alegre: Artes Médicas, 1997.

Vivian, A. G. (2005). O desenvolvimento emocional de um bebê em uma família numerosa: uma aplicação do método Bick. Projeto de Dissertação de Mestrado não publicado, Programa de Pós-Graduação em Psicologia do Desenvolvimento, Universidade Federal do Rio Grande do Sul. Porto Alegre, RS.

Winnicott, D. W. (1971). O brincar e a realidade. (J. O. A. Abreu, V. Nobre, Trads.). Rio de Janeiro: Imago Editora, 1975.

Wirth, A. F. (2000). Aplicação do método de observação de bebês em uma UTI neonatal. Em Caron, N. A. (Org.). A relação pais-bebê: da observação à clínica (pp. 207-232). São Paulo: Casa do Psicólogo.

Recebido em 2 de julho de 2006 Aceito para publicação em 2 de novembro de 2006 